5. Gatchel, R. J., 1996. Apud Hortense, P. “Escalonamento comparativo de diferentes dores nociceptivas e neuropáticas, por meio de métodos psicofísicos variados". Tese de doutorado, Escola de Enfermagem de Ribeirão Preto. USP. 2007.

6. Foucault, M. 1980. Apud Hortense, P. “Escalonamento comparativo de diferentes dores nociceptivas e neuropáticas, por meio de métodos psicofísicos variados". Tese de doutorado, Escola de Enfermagem de Ribeirão Preto. USP. 2007.

7. Ferreira, J., 1998. Apud Hortense, P. "Escalonamento comparativo de diferentes dores nociceptivas e neuropáticas, por meio de métodos psicofísicos variados". Tese de doutorado, Escola de Enfermagem de Ribeirão Preto. USP. 2007.

8. Helman CG, 1994. Apud Hortense, P. "Escalonamento comparativo de diferentes dores nociceptivas e neuropáticas, por meio de métodos psicofísicos variados". Tese de doutorado, Escola de Enfermagem de Ribeirão Preto. USP. 2007.

9. Cahana, A. "Pain and philosophy of the mind". Pain Clinical Updates. Vol.XV, no.5. July 2007.

10. Damásio, A. R. O erro de Descartes, emoção, razão e o cérebro humano. Companhia de Letras. São Paulo. 1994.

11. Ajuriaguerra, J.D. \& Hécaen, H. Le córtex cerebral, pg 41,43. Masson et Cie, França, 1960.

12. Tolosa AP, Canelas HM. Propedêutica neurológica, p.248. Sarvier. 1971.

13. Pasternak . "22nd Annual Scientific Meeting". Chicago. 2003.

14. Ross, Elisabeth Kübler. Sobre a morte e o morrer. Martins Fontes. 1969.

15. Melzack, R. "The short-form McGill Pain Questionnaire". Pain. Vol.30, no.2, pp.191-7. 1987.

16. Flor, H. \& Hermann, C. Psychosocial aspects of pain. IASP Press. 2004.

17. Zhukovsky, D. S. "22nd Annual Scientific Meeting". Chicago. 2003.

18. Porto, D. \& Garrafa, V. "Bioética de intervenção: considerações sobre a economia de mercado". Bioética, Vol.13, no.1, pp.11-123. 2005.

19. Von Korff, M.; LeResche L. Epidemiology of pain. The paths of pain 1975-2005. In: Merskey, A.; Loeser, J. D.; Dubner, R. IASP Press. 2005.

\section{BIOÉTICA, DOR E SOFRIMENTO}

\author{
José Paulo Drummond
}

"A dor não surge apenas por estimulação periférica, mas também
por uma experiência da alma, que reside no coração".
Platão

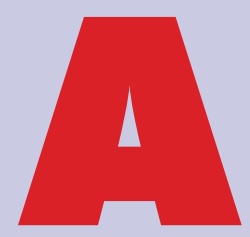

bioética originou-se das questôes concretas, relacionadas à vida, em geral, e suscitadas, recentemente, dentro das áreas médica, ecológica e social, em função dos respectivos desenvolvimentos. $\mathrm{Na}$ medicina, surgiram situaçôes existenciais que exigiam ampla abordagem, ultrapassando os limites de uma visão especializada. Entre essas questôes, podemos citar aquelas relacionadas à genética, à reprodução humana, aos transplantes de órgãos, ao aborto, à cirurgia fetal, à qualidade de vida, à reanimação, ao direito de morrer, à repressão psiquiátrica, à pesquisa etc. Em outras palavras, as decisões clínicas, em certas circunstâncias, tornaram-se tão multifacetadas que, parafraseando um dito famoso relativo à guerra e aos militares, a medicina transformou-se então em algo demasiado complexo para ser discutida apenas por médicos. A fim de se evitar um reducionismo profissional, verificou-se a necessidade de um diálogo pluridimensional e interdisciplinar, entre peritos e leigos, o que constitui a própria essência e metodologia de trabalho da bioética.

PRINCÍPIOS DA BIOÉTICA A bioética pode ser definida como "o estudo sistemático da conduta humana no âmbito das ciências da vida e da saúde, enquanto esta conduta é examinada à luz de valores e princípios morais" (1). Quem cunhou o termo, embora com um sentido distante do atual, foi um oncologista, da Universidade de Wisconsin, Van Rensselaer Potter, em seu livro Bioethics: bridge to the future (2). A bioética ultrapassa os limites dos códigos deontológicos profissionais, cujas normas morais e jurídicas, embora necessárias, transformam-se num esquema excessivamente redutor para acolher as mudanças amplas e profundas que se processam no âmbito da saúde, além de apresentarem certo viés corporativista. Neste artigo nos restringiremos à consideração dos princípios fundamentais da bioética, em sua relação com a assistência à dor e ao sofrimento. Beauchamps e Childress (3), ampliando os objetivos do Relatório Belmont sobre pesquisas, publicado em 1978 pela Comissão Nacional criada pelo Congresso norte-americano, reafirmaram o seu paradigma ético, que constituía uma referência prático-conceitual, consolidada sobre três princípios: o da beneficência, o da autonomia e o da justiça, interpretados à luz do utilitarismo. É conhecida como a tríade bioética, cuja articulação, nem sempre harmoniosa, repousa no médico (pela beneficência), no doente (pela autonomia) e na sociedade (pela justiça). O princípio de beneficência e o seu correlato de não maleficência derivam do preceito hipocrático Primum non nocere (primeiro, não causar danos), logo Bene facere (fazer o bem), e resumem-se na obrigação moral de agir em benefício do outro, seja quem for e em 
quaisquer circunstâncias. O princípio de autonomia, em sentido lato, implica em não submeter as ações autônomas a limitações controladoras alheias: sob um aspecto, não deve ser confundido com o individualismo e, sob outro, confronta com as formas de manipulação, que consideram o homem como objeto. O princípio de justiça ou de equidade seria a distribuição equânime de bens e serviços, segundo alguns, ou o respeito aos interesses de cada um, conforme outros.

O PRINCÍPIO DE BENEFICÊNCIA Este princípio encerra-se no preceito de fazer o bem e evitar o mal, isto é, maximizar os benefícios e minimizar os riscos potenciais. A profissão médica, teoricamente, seria a própria encarnação desse princípio em seu objetivo de aliviar a dor e de curar o doente, independente de identidades e contextos. O exemplo clássico acha-se na parábola do bom samaritano e na noção de próximo que ela sustenta. Pode-se considerar como bons, em sentido geral, os fins que contribuem para o crescimento de um ser humano, ajudando-o a conseguir sua totalidade ou sua perda menor. Todavia, é preciso reconhecer que, no ambiente hospitalar, o desenvolvimento histórico da própria instituição gerou três paradigmas concorrentes: o técnico-científico, o comercial-empresarial e o ético-humanitário. Embora sejam inevitáveis os conflitos resultantes da confrontação desses paradigmas, não seria demais colocar que o científico e o econômico deveriam estar a serviço do ser humano e não ao contrário (4). A organização tecnicista do espaço nosocomial, a estrutura cartesiana e positivista da assistência, o estilhaçamento técnico-operacional e os modos de produção originaram a chamada medicina de órgãos, em que se pratica certo esquartejamento científico e epistemológico do paciente, enquanto objeto, em prejuízo de uma abordagem holística. Ao tentar reduzir o mundo a equações e algoritmos, a ciência se distanciou da vida, gerando uma medicina tecnicista e informatizada, que enxerga coisas em vez de semblantes. Recentemente, da parte da enfermagem, surgiu o critério da dor como 5o sinal vital, aliado aos de respiração, temperatura, pulso e pressão arterial, cujo registro no prontuário torna a dor mais visível e, em decorrência, mais exposta ao tratamento (5).

Em relação à dor, especificamente, o princípio da beneficência defronta-se com três questôes básicas: 1) o tratamento inadequado; 2) o descaso assistencial; e 3) a postura paternalista.

O tratamento inadequado, mesmo em regiōes industrialmente desenvolvidas, ainda é constatado com frequência, por mais que, nas duas últimas décadas, tenha sido denunciado, analisado e reavaliado. Possivelmente, os motivos principais dessa insuficiência terapêutica sejam a desinformação sobre aspectos da dor e a aplicação imprópria dos conhecimentos farmacológicos disponíveis.

$O$ descaso assistencial tem razões bastante complexas e multifacetárias, as quais deixam transparecer certo entendimento da dor e da doença como expiação de culpa, cuja origem encontra-se em concepções judaico-cristãs, que impregnam nossa cultura ocidental. Vejam, por exemplo, entre os relatos bíblicos, a postura dos amigos de Jó, em relação às aflições e às moléstias que o atingiram (Livro de Jó), bem como a pergunta dos discípulos de Jesus sobre o cego de nascença (Jo 9, 1-3), muito embora a mensagem libertadora de Jesus, no sentido espiritual e sociopolítico do termo, oponha-se a essa ótica penalizadora da doença e do sofrimento (6). No entanto, estudos sociológicos (7) ainda hoje nos revelam que, apesar de nossa modernidade, é grande a tentação de associar a ideia de dor à ideia de transgressão. A concepção da dor (doença) como punição merecida por alguma conduta reprovável ainda está profundamente enraizada no inconsciente de nossa linguagem e nas nossas consciências contemporâneas. A palavra anglo-saxônica pain (dor) provém do latim poena e do grego poiné, ambas significando castigo. Disto resulta, por parte do terapeuta, certa aceitação acrítica, certo conformismo dolorista, verdadeira banalização da dor do paciente. Outra causa dessa omissão terapêutica advém da visão da dor como sintoma importante, como sinal de alerta biológico, como de fato o é, principalmente no caso da dor aguda, mas não como verdadeira afecção, como é entendida atualmente, sobretudo no contexto da dor crônica. Interessante que desde os tempos hipocráticos (8), a dor era considerada uma doença importante: "Sedare dolorem divinum opus est".

A postura paternalista faz com que o princípio da beneficência seja externado em relações terapêuticas assimétricas e em comportamento profissional impositivo. Tal atitude provém, ao menos, de três situações: 1) o autoritarismo médico, de raízes históricas, manifestado nas relações professor/aluno e médico/paciente; 2) a vulnerabilidade do paciente, implícita na afecção dolorosa crônica; e 3) a medicalização da vida, isto é, a onipresença social, às vezes devastadora, das concepções médicas.

O ensino médico clássico é dirigido no sentido da busca da autoridade (seja um livro-texto, um especialista ou outro colega mais experiente), como meio de resolver dúvidas de conduta ou lacunas de saber, e esta formação resvala, muitas vezes, em formas impositivas na relação médico/paciente.

Além de vulnerável, o paciente atingido pela dor crônica mostra-se, frequentemente, depressivo, de maneira que o protecionismo paternalista pode desenvolver grandes dependências e regressões, que podem acentuar o sentido de fuga, de que a doença se reveste muitas vezes. Mas, note-se que a intenção de fugir é própria de quem se acha prisioneiro. A pessoa é tanto mais livre quanto menos procura evadir-se (de si próprio, da sociedade, da vida).

Enfim, a medicalização da saúde, a colonização médica da vida, segundo Illich (9), cria ao paciente situações de subordinação e transforma o aparelho biomédico do sistema industrial em instituição quase autocrática. Evidentemente, existem outras maneiras de cura fora do campo médico, embora a hegemonia da medicina, invadindo toda a área do cuidado e, em consequência, todo o espaço da saúde, engendre um processo de medicalização dos problemas sociais. Assim, inúmeros aspectos da experiência humana, inclusive a dor e o sofrimento, foram subtraídos ao reino do autoconhecimento para serem transferidos ao império da medicina, com a aura que lhe conferem a tecnologia e o determinismo biológico.

O paternalismo contradiz, em termos, o segundo princípio da bioética, o de autonomia. Todavia, paternalismo e autonomia não podem ser considerados reciprocamente excludentes, de modo absoluto e utópico, mas seriam antes complementares, embora em sentido inversamente proporcional: a uma grande autonomia corresponderia um leve paternalismo e vice-versa. 
O PRINCÍPIO DE AUTONOMIA A bioética, nestes tempos de mercantilização de quase todos os valores, quer ser um clamor pela dignidade e autonomia da pessoa e pela qualidade de vida. Devemos começar, por conseguinte, pelas definições de autonomia e de pessoa, que são, estreitamente, relacionadas.

O conceito de autonomia tem suas bases filosóficas em Kant, do ponto de vista deontológico, e em Stuart Mill, sob o aspecto utilitarista. Em ambos, autonomia identifica-se com as ideias de dignidade, liberdade e responsabilidade individuais. Não deve ser confundida com o individualismo, como doutrina que considera o indivíduo como a realidade mais essencial ou como o valor mais elevado. Também chamado de princípio de consentimento (10), o princípio de autonomia exerce-se pela consideração, na relação terapêutica, do paciente como sujeito, ou seja, participante ativo e esclarecido, e não apenas como objeto, isto é, recipiente passivo e desinformado. Configura o direito à autodeterminação e sua violação está em tratar as pessoas como meio e não como fim.

A definição de pessoa supõe a afirmação da atitude de conscientização e a negação dos instrumentos de manipulação. Excede a noção do indivíduo por seu aspecto relacional, por sua inserção social. Embora possam haver aspectos conflitantes, de natureza histórico-cultural, ético-jurídica e bio-psíquica, entende-se, geralmente, por pessoa o ser humano consciente, dotado de corpo, razão e vontade, autônomo e responsável. Todavia, a definição de pessoa não é ainda uma questão de fato ou mesmo de direito, mas uma tarefa humana que urge se construir ou desvendar.

Enfim, aliado às três regras metodológicas do discernimento ético (solidariedade, dignidade e responsabilidade), o princípio de autonomia, em vez de se fixar na noção estática de norma, pode tornar-se um instrumento, um auxílio dinâmico da investigação bioética: uma passagem do código para a vida. Enquanto uns pedem regras e preceitos, que lhes são ditados e que lhes oferecem o conforto (mas também as limitações) do conformismo, outros procuram, mesmo com riscos, a coerência entre o ser e o agir, entre interioridade e exterioridade, entre as convicçōes mais profundas e as condutas mais cotidianas.

Atualmente, a possibilidade ampliada de informaçōes mais fidedignas e de conscientização crescente atenua a capacidade de manipulação, cujos alicerces encontram-se, tanto no médico como no paciente, na espantosa falta de compreensão do próprio homem, numa civilização grandemente desenvolvida, do ponto de vista tecnológico, mas atrofiada, quanto à ética e à sensibilidade. $\mathrm{O}$ encontro terapêutico, necessariamente fundado na confiança, estabelece-se, então, como diálogo e parceria (the patient as a partner), como permuta de informações, o doente assumindo, dentro de suas possibilidades, a condição de sujeito, nos espaços de decisão e tratamento. Além do lado propriamente ético, este comportamento produz resultados pragmáticos, no sentido de maior frequência às consultas e de maior aderência às prescriçóes (11). Ainda que desde Hipócrates tenha sido ressaltada a importância da participação do paciente no processo de cura, por meio de um dos seus aforismos ("oponha-se ao mal o doente, juntamente com o médico"), apenas recentemente criou-se a denominação medicina centrada no paciente para designar o respeito aos seus valores e preferências e a sua inclusão na própria equipe terapêutica, no modelo deliberativo de tomada de decisão e na discussão aberta do prognóstico (12). Revoga-se, desta maneira, o significado, resultante de uma medicina essencialmente mecanicista, da mudez do terapeuta ou, pelo menos, de sua grande parcimônia de palavras, gestos e sentimentos ("sisudez" e "neutralidade"), como sinal de saber científico, e se busca o sentido terapêutico da palavra, do diálogo pessoal e intersubjetivo - o encontro entre um "eu" e um "tu" reais e não a mera proximidade entre dois personagens quase virtuais.

De tudo o que foi dito, especificamente, sobre a relação médico/ paciente com dor, ressalta-se a importância de um relacionamento sujeito/sujeito e não sujeito/objeto. O conceito tradicional dessa relação firmava-se, basicamente, no princípio deontológico de certa beneficência paternalista, em que do médico exigia-se competência e do paciente, apenas uma colaboração complacente e passiva (13). Estruturou-se, assim, uma relação sujeito/objeto, à qual não é alheia a coisificação das pessoas, resultante do mercantilismo capitalista. É preciso afirmar, incisivamente, que a virtude maior do paciente, bem como do leigo nas igrejas e do aluno nas escolas, não éa obediência, mas a responsabilidade. (Quantos crimes não foram perpetrados em nome da obediência, inclusive da "santa obediência"!). Enquanto, na criança, uma obediência esclarecida possa ser a orientação mais eficaz, no adulto, uma responsabilidade assumida é a marca dominante da ética.

Ao abordar o tema autonomia e dor não podemos deixar de nos referir à colocação recente do alívio da dor, ao menos a aguda em nosso entendimento, como direito humano (14), estribada no art. 5o da Declaração de Direitos Humanos: "Ninguém será sujeito (...) a tratamento degradante e desumano". Parte-se do pressuposto de que toda dor, especificamente a aguda, pode e deve ser tratada adequadamente. No entanto, o direito de não sofrer não se acrescenta apenas aos demais direitos, mas testemunha ainda, de modo privilegiado, a tendência, própria do indivíduo moderno, a subordinar os direitos vinculados à liberdade aos direitos relacionados à crença e a trocar, assim, sua autonomia pela promessa de escapar um dia àquilo que Tocqueville, citado por Jerome Porée (15), chamava, num texto profético, "o esforço de pensar e a pena de viver". Não se trata de desenvolver uma espécie de nostalgia pseudo-ecológica de um tempo em que se sofria "naturalmente" ou "autenticamente", mas de se assinalar os pressupostos e as consequências de uma compreensão técnico-científica da dor, que originou uma algiofobia, uma desvalorização absoluta da sensação dolorosa, uma recusa de questionamentos e uma ausência de coragem (16), em suma, a incapacidade de sofrer. Como corolário, verifica-se redução do limiar da dor. Todavia, não é que o sofrimento em si dignifique a pessoa, pois isso seria a justificativa de toda violência e de toda tirania (a ideologia da vítima culpada), mas o fato de ultrapassá-lo é que a engrandece (17). 
O PRINCÍPIO DE JUSTIÇA O princípio de justiça ou de equidade diz respeito à obrigação de igualdade de tratamento, com referência à equipe de saúde, e de justas políticas de saúde, com relação ao Estado. Dos três princípios, este é o mais recente na consciência do médico e na percepção social. Já foi dito que a origem da bioética deveu-se às questôes de ordem moral, originadas do progredir da medicina e do surgimento de situaçôes clínicas inauditas. Mas, afirma-se também que o seu nascimento deu-se no contexto do conflito entre o código deontológico, restrito à corporação médica, e as reivindicações de transparência e responsabilidade pública erigidas pelos movimentos sociais (18).

Uma das divisões da bioética considera a microética, ocupada com casos individuais e atendo-se, basicamente, à relação paciente/médico, às decisões inusitadas e às pesquisas; a macroética, orientada para os aspectos sociais, para o impacto dessas decisōes sobre a sociedade e para o impacto da sociedade sobre as pessoas; e a mesoética, intermediária das anteriores, que faz a íntima ligação do individual com o social (19). Outra classificação, proposta por Berlinguer (20), divide a bioética em duas partes: a de fronteira ou de situaçôes limites, que trata das inovaçôes tecnológicas, e a cotidiana, que se abre para o campo social. Enquanto a primeira volta-se para os países desenvolvidos, a segunda contempla questôes mais pertinentes ao Terceiro Mundo. De tudo isso, depreende-se a dimensão social da bioética, que pretende exercer a crítica das modalidades assistenciais, bem como das políticas de saúde, no que se refere à distribuição e à inversão dos recursos. Também procura atingir as ideologias dominantes, como pode ser visto neste texto de Berlingue (20):

\footnotetext{
"De qualquer forma, pode-se afirmar que a medicalização da vida, expressão que foi muito usada nos anos cinquenta, como crítica à tendência da medicina em ocupar e apropriar-se dos espaços e dos períodos mais cruciais da existência humana, entrelaça-se também com a mercantilização da medicina, com a tendência a transformar, em mercadoria ou em dinheiro, cada parte do corpo e cada ato relativo à vida e à saúde".
}

Sob outro prisma, se o princípio da autonomia torna interpessoal a relação terapêutica e o paciente assume a posição de sujeito, em sua atuação social como pessoa, o princípio de justiça provoca o médico a sair do âmbito restrito daquela relação para pensar sua inserção comunitária, seu desempenho como cidadão. Cabe aos médicos mais conscientes, bem como aos clérigos e aos educadores, o dever de renunciar ao seu papel infantilizador e alienante, a fim de assumir uma postura esclarecedora, denunciadora e profética. Além disso, a prática profissional cria, muitas vezes, um conflito para o médico, entre sua responsabilidade para com os pacientes individuais e sua responsabilidade para com a sociedade: no primeiro caso, o objetivo é maximizar a qualidade de vida e, no segundo, otimizar a utilização dos recursos disponíveis (21). Os médicos alegam que a saúde não tem preço, porém os administradores sabem que ela tem um custo. Por outro lado, a pesquisa, suportada, financeira e administrativamente, por empresas que visam, basicamente, o lucro, resultante da produção de conhecimentos, cria, muitas vezes, conflito de interesses.
Propriamente, no que tange ao princípio da justiça e à assistência do paciente com dor, ressalta, de início, o número limitado de serviços especializados em contrapartida à enorme demanda, especialmente dos casos de dor crônica. Além disso, aquela assistência cada vez mais torna-se tecnologicamente sofisticada, custosa e multidisciplinar, o que muitas vezes obriga a equipe de saúde a erigir critérios preferenciais (fundamentados em quê?) na utilização de tratamentos de alta tecnologia, configurando a famosa escolha de Sofia, em referência ao filme com este título (direção de Alan J. Pakulam 1982). Dizer que "saúde é direito de todos e dever do Estado", como rege a Constituição Federal no art. 196, e não prover o acesso do paciente aos meios diagnósticos e terapêuticos, é favorecer a criação de uma dupla moral: uma proclamada e outra praticada. Nas últimas décadas, a figura principal da injustiça e do sofrimento social não é tanto a exploração no sentido marxista do termo, mas a exclusão, como decorrência do neoliberalismo. Além disso, o indivíduo, desprovido de "certezas", religiosas ou morais, consumista ávido, experimenta uma profunda sensação de vazio e insegurança, numa sociedade que não mais integra o sofrimento e a morte como dados inelutáveis da condição humana.

Outra característica da problemática em questão é a tendência atual a se preferir o conceito de equidade ao de desigualdade. O primeiro, ao contrário do segundo, engloba o critério descritivo, sugere uma análise distintiva das causas, considera as omissōes e as açōes humanas capazes de ampliar ou reduzir as diferenças, põe em jogo, com as oportunidades, a aquisição das capacidades aptas a atingir uma finalidade. A iniquidade na saúde refere-se a diferenças que são não-necessárias e evitáveis, ao mesmo tempo em que são inaceitáveis e injustas. A propósito, é de se notar, atualmente, um enfraquecimento progressivo da Organização Mundial de Saúde em favor do Banco Mundial, cujas orientaçōes, sobretudo nos países subdesenvolvidos, constituem a diretriz efetiva das políticas de saúde.

DOR E SOFRIMENTO O sofrimento é quase sempre associado ou mesmo confundido com a dor, devido a raízes históricas, religiosas e culturais. Fala-se de sofrimento e de dor nos mais variados contextos, tais como pobreza, catástrofes, opressão etc, nos quais não existe dor, do ponto de vista orgânico. O que têm de semelhante é a emoção negativa ou ameaçadora da própria vida, embora possamos sofrer sem ter dor e ter dor sem sofrer. O sofrimento não é a dor, mas pode ser evocado ou enfatizado pela mesma.

A dor física (nocicepção) é uma questão biológica, uma vez que sua neurofisiologia é a mesma em todos os seres humanos, porém, sua percepção e sua vivência são culturalmente construídas, isto é, são personalizadas. O sofrimento é mais englobante do que a dor, pois, provoca, essencialmente, redução da qualidade de vida, como resposta negativa, induzida também por medo, ansiedade, estresse, perdas e outros estados psicológicos. A dor requer um sentido ou explicação física e existencial que, não sendo encontradas, interferem no próprio sentimento, em termos de frustração, ansiedade e depressão. Neste caso, o sofrimento é a decorrência dramática da falta de compreensão e de significado do fenômeno álgico. A dor exige compreensão racional e o sofrimento pede entendimento afetivo. 
A dor e o sofrimento exprimem uma experiência global, a síndrome da existência vazia, ao menos que se lhes encontre um sentido, imanente ou transcendente, capaz de preenchê-la. A dor é amplificada, muda-se em sofrimento pelo abandono e pela rejeição. No entanto, em que pese o paralelismo e as diferenças, qualitativas e quantitativas, entre dor e sofrimento, o problema da relação entre ambos remete, em última instância, à questão da relação mente-corpo, porém, se evitando o dualismo clássico, cartesiano, o qual, nas palavras de Gusdorf (22), se desdobra "numa medicina de cadáver vivo e numa psicologia da alma sem corpo".

Podemos traçar o seguinte paralelismo entre dor e sofrimento: a dor grita, o sofrimento lamenta-se; a dor transita, o sofrimento esmaga; a dor mutila, o sofrimento desintegra; a dor é percepção presente, um "agora" sensível, o sofrimento é passado, memória, um "sempre" subjacente; a dor é matéria que se faz cognição, o sofrimento é (re) sentimento que se faz matéria (lesōes psicossomáticas); a dor aponta para um local, o sofrimento é um todo difuso; a dor necessita falar, se manifesta por interrogações e interjeiçôes, o sofrimento tende ao silêncio, a se exprimir por lágrimas, na expressão de santo Agostinho, este "colírio da alma", o coração liquefeito a dissolver os nós. De certo modo, para determinado paciente e em dado momento, o seu sofrimento é a leitura racional e o significado emocional de sua própria dor - leitura e significado que se reportam ao seu passado, permeados por memórias, esperanças, preconceitos e outras idiossincrasias cognitivas internas.

Daí a necessidade de se encarar o fenômeno doloroso sob o tríplice aspecto biopsicossocial. Em alguns casos, pode-se acrescentar a dimensão espiritual, que está vinculada a valores éticos e não à mera religiosidade. A abordagem do paciente, por conseguinte, não deve ser feita dentro de um prisma vertical de dominação, mas mediante uma aproximação de empatia e acolhimento, perante toda a complexidade do ser humano. É mister estimular o paciente como agente de sua própria cura, como já recomendava a medicina hipocrática e ajudá-lo a desenvolver responsabilidade e iniciativa, ao invés de limitá-lo mediante sentimentos de culpa e normas disciplinares. Enfim, a assistência à dor demanda competência, medicação e cuidados especializados, enquanto a terapêutica do sofrimento solicita atenção, aceitação e solidariedade. A dor crônica e o sofrimento implícito são desestabilizadores, destrutivos. Ora, o antônimo de destruir é criar. Logo, a criação, não apenas no sentido artístico do termo, mas na mais ampla acepção de encontrar outros objetivos existenciais, é o antídoto específico para o processo desintegrador do sofrimento. $\mathrm{E}$ a criação maior é a construção de uma vida nova, que inclua o entendimento, patológico e teleológico, da doença.

Há que se seguir, portanto, dois propósitos fundamentais: 1) o de se evitar a manipulação; e 2) o de se sobrepor o cuidar ao curar.

Quanto à manipulação, as ideologias e a publicidade produzem adultos infantilizados, precocemente envelhecidos e despidos de espírito crítico, ou seja, indivíduos facilmente influenciáveis, dentro de uma conceituação estática da sociedade. O alicerce da manipulação é sempre a consideração do homem/mulher como objeto, visto como meio e não como fim. Procura-se evitar esse controle despersonalizante por meio do relacionamento dialogal, horizontal e democrático, criando-se um espaço onde as informações permutadas e a confiabilidade gerem conscientização e auto-estima. A questão situa-se no optar, de um lado, por uma medicina restritiva, que valoriza um imaginário utilitarista e mercantil, ou, de outro lado, por uma medicina ampliada, que valoriza um imaginário solidário e democrático. Também deve-se evitar a visão reducionista da doença e da saúde como questões de ordem exclusivamente orgânica ou fisiológica, buscando entendê-las como produto da relação da pessoa com o meio ambiente e as instituiçôes sociais (23). A saúde está intimamente vinculada à totalidade do ser humano.

Em relação ao cuidar, a complexidade do fenômeno álgico exige uma apreciação mais ampla do que a estrita visão organicista, expressa no tratamento farmacológico. A vulnerabilidade provocada pela dor (doença) exige uma resposta chamada cuidado. Em senso estrito, cuidado é, na relação terapêutica, o debruçar-se o médico sobre a angústia do paciente, enxergar mais do que olhar, escutar mais do que ouvir, não somente suas palavras, mas também suas hesitaçōes, seus silêncios; é procurar entender, não apenas o mecanismo nociceptivo, mas o significado daquela dor para aquele paciente; é saber que o resultado terapêutico não resulta apenas da prescrição medicamentosa, mas de toda uma postura compreensiva e solidária. É no encontro terapêutico, no espaço relacional, que se reconhece o rosto do outro, no dizer de Lévinas (24), e que se vivencia a alteridade, se percebe o próximo e nasce a transcendência, a responsabilidade e a compaixão, constituintes intrínsecos do cuidar. Em senso lato, cuidado não é somente uma categoria que define o ser humano, mas que também nos permite compreender o universo, pois é tão ancestral quanto o cosmo em evolução, ao constituir a condição prévia que permite o eclodir da inteligência e da amorosidade.

CONCLUSÕES Procuramos assinalar os fundamentos e os objetivos da bioética e suas relações teóricas e práticas com a assistência à dor e ao sofrimento. Tentamos fazê-lo, balizando esse paralelismo por meio dos três princípios básicos da bioética: beneficência, autonomia e justiça. Estes princípios, de fato, são válidos como orientação nas questôes bioéticas, porém, conviria fundamentá-los, filosoficamente, por meio do conceito de pessoa, entendida como interlocutor válido, a fim de apreciar em sua plenitude a legitimidade intersubjetiva. Além disso, trata-se de princípios prima facie, ou seja, que precisam ser seguidos sempre, desde que não entrem em conflito; nesta situação, eles nos obrigam a refletir e ponderar, de maneira que a decisão correta deva ficar a cargo das pessoas por eles afetadas (ética do discurso) (25). De maneira mnemônica, poderíamos dizer que a bioética é representada por três Rs: racionalidade, responsabilidade e resistência. Uma racionalidade que não exclui a dimensão intuitiva; uma responsabilidade que se quer cada vez mais expandida (familiar, social, planetária); e uma resistência que enfrenta os preconceitos e os ídolos de hoje e que se volta para um amanhã de maior dignidade e de vida mais plena.

Quanto à dor e ao sofrimento, eles requerem duas posturas intrínsecas, segundo Vergely (17): "a sensibilidade, ou seja, a consciência de estar mal, integralmente falando, e a paciência, isto é, a capacidade de suportá-los (...). A sensibilidade precisa da paciência e vice-versa. 
Uma sensibilidade que não se internaliza, mas que desperta a vida, e uma paciência que não se acomoda, mas que releva a indignação. Mediante estes dois atributos, a pessoa relaciona-se com a própria vida e a vida, com a pessoa (...). Sensibilidade não é pura passividade, nem paciência é resignação: exprimem a virtude de questionar, refletir e reagir". Observe-se que o sofrimento bom é um mito, mas o sofrimento sem causa é o desespero. Quando, diante do mal, nos limitamos a gritar ou então tentamos negá-lo, acabamos por fazer o jogo do mal.

Em suma, a preocupação mais profunda da bioética é com a qualidade de vida, cuja limitação é uma decorrência maior ou menor da presença da dor e do sofrimento, que constituem um dos temores fundamentais do mundo contemporâneo, onde o tema do vulnerável e do sofredor ocupa, em nossa consciência, o locus antes preenchido pelas elucubraçōes do cogito ou do indivíduo puramente racional. Esta preocupação concretiza-se, na prática, pelo cuidar, na acepção ampla do verbo que lhe atribui Leonardo Boff (26). Tornar-se ético é começar a pensar e a agir, de modo honesto, correto e coerente. Toda ética autêntica nasce do respeito racional, mas profundamente amoroso, pela vida, por qualquer forma de vida. A famosa afirmação de santo Agostinho, "ama e faze o que quiseres", foi sepultada, ao longo dos séculos, pelo peso da rigidez deontológica e pela espessura da objetividade utilitarista. Talvez essas palavras sejam uma lembrança oportuna, no presente momento, quando a Terra está adoecida por agressões desatinadas ao equilíbrio ecológico, e quando a guerra ameaça transformar-se em desvario coletivo ou em inominável big business para alguns.

José Paulo Drummond é livre-docente e professor adjunto da Faculdade de Medicina da Universidade Federal do Rio de Janeiro (UFRJ).

\section{REFERÊNCIAS BIBLIOGRÁFICAS}

1. Reich, W. T. (org.). Encyclopedia of bioethics. New York: The Free Press, Vol.I. p. XIX. 1978.

2. Potter, V. R. Bioethics: bridge to the future. Prentice Hall, Englewood Cliffs (NJ), 1971.

3. Beauchamps, T. L.; Childress, J. F. Principles of biomedical ethics. Oxford: Oxford University, 1989.

4. Martin, L. M. "A ética e a humanização hospitalar". In: Pessini, L.; Bertachini, L. (orgs.). Humanização e cuidados paliativos. São Paulo: Loyola. pp.31-50. 2004.

5. Chaves, L. D.; Leão, E. R. Dor $-5^{\circ}$ sinal vital. Curitiba: Edit. Maio, 2004.

6. Gutierrez, G. Teologia da libertação: perspectivas. São Paulo: Loyola, 2000.

7. LeBreton, D. Anthropologie de la douleur. Paris: Métailié. pp.104-6. 1995.

8. Hipócrates. Epidemics. Vol. I. Massachussets: Harvard University Press, 1962.

9. Illich, I. A expropriação da saúde. Rio de Janeiro: Nova Fronteira, 1975.

10. Engelhardt Jr., H. T. Fundamentos de bioética. São Paulo: Loyola, 1998. p.135-68.
11. Greenfield, S.; Kaplan, S.; Ware, J. E. "Expanding patient involvement in care: effects on patient outcomes". Ann Intern Med, Vol.102, pp.520-8. 1985.

12. Laine, C.; Davidoff, F. "Patient-centered medicine". Jama, Vol.275, no.2, pp.152-6. 1996.

13. Szasz, T. S.; Hollender, M. H. "A contribution to the philosophy of medicine: the basic models of the doctor-patient relationship". Arch Intern Med, Vol.97, pp.585-92. 1956.

14. Brennan, F.; Cousins, M. J. "Pain relief as a human right". Pain Clinic Updates, Vol.XII, no.5, pp.1-4. 2004.

15. Porée, J. “La sensation douloureuse existe-t'elle? Neurophysiologie, psychologie et phenoménologie". In: VV. AA. A dor e o sofrimento: abordagens. Porto: Campo das Letras, pp.103-24. 2001.

16. Buytendiyk, F. J. J. De la douleur. Paris: PUF, pp.4-8. 1951.

17. Vergely, B. La souffrance. Paris, Gallimard, pp.77-80.1997.

18. Barreto, V. "Problemas e perspectivas da bioética". In: VV AA Bioética no Brasil. Rio de Janeiro: Espaço e Tempo Ltda., pp.53-76.1999.

19. Durand, G. A bioética - natureza, princípios, objetivos. São Paulo: Paulus, pp.17-30.1995.

20. Berlinguer, G. Ética da saúde. São Paulo: Hucitec, p.44. 1996.

21. Sackett, D. L. The doctor 's (ethical and economic) dilemma. London: Office of Health Economics. 1996.

22. Gusdorf, G. Dialogue avec le médicin. Genève, Editions Labor et Fides, pp.13-14. 1995.

23. Martins, P. H. Contra a desumanização da medicina. Rio de Janeiro: Vozes. p.143. 2003.

24. Lévinas, E. Éthique et infini. Paris, Fayard. 1982.

25. Habermas, J. Conciencia moral y acción comunicativa. Barcelona: Península. 1985.

26. Boff, L. Saber cuidar. Petrópolis, Vozes. 1999. 